Available online at

http://www.anpad.org.br/bar

BAR, Rio de Janeiro, v. 10, n. 3, art. 1, pp. 239-262, July/Sept. 2013

\title{
Factors Affecting Mobile Users' Switching Intentions: A Comparative Study between the Brazilian and German Markets
}

\author{
Rodrigo C. Martins \\ E-mail address: Rodrigo_Ciaravolo@gmail.com \\ Colgate-Palmolive
}

Av. Pref. Dulcidio Cardoso, 1640 / 1705, Bld.1, 22620-311, Rio de Janeiro, RJ, Brazil.

Luis Fernando Hor-Meyll

E-mail address: hormeyll@iag.puc-rio.br

Pontifícia Universidade Católica do Rio de Janeiro - IAG/PUC-Rio

IAG Business School, R. Marques de São Vicente, 225, 22451-900, Rio de Janeiro, RJ, Brazil.

Jorge Brantes Ferreira

E-mail address: jorge.brantes@iag.puc-rio.br

Pontifícia Universidade Católica do Rio de Janeiro - IAG/PUC-Rio IAG Business School, R. Marques de São Vicente, 225, 22451-900, Rio de Janeiro, RJ, Brazil.

Received 4 April 2011; received in revised form 2 May 2013 (this paper has been with the authors for four revisions); accepted 8 May 2013; published online $1^{\text {st }}$ July 2013. 


\begin{abstract}
In the competitive wireless market, there are many drivers behind customer defection. Switching barriers, service performance, perceived value in carriers' offers, satisfaction and other constructs can play a pivotal role in customer switching processes among carriers. This study attempts to compare the influence of these factors, taking into account cultural similarities and dissimilarities, between Brazilian and German mobile users. A survey was conducted on two samples, comprising 202 users in Brazil and 200 users in Germany, with culture being employed as a context variable to compare their behavior. Analysis by means of multi-group structural equation modeling suggests that, in both countries, customer satisfaction, service performance and perceived value have important roles in defining customer switching intentions, while switching barriers did not prove to have significant effects upon switching behavior. The results also suggest that the two cultures are sufficiently similar (considering the sample and the variables involved in the model) to not present differences in the studied consumer behavior, except for the effect of service performance upon satisfaction.
\end{abstract}

Key words: switching intentions; satisfaction; mobile telephony; cross-cultural comparison; cultural distance. 


\section{Introduction}

Latin America, with 530 million wireless subscribers, has surpassed Western Europe to become the second largest cellular market in the world. The Southern Cone countries, notably Brazil, the region's largest market, were largely responsible for this advance.

With over 203 million mobile phones in operation and penetration of approximately 104 mobile lines per 100 inhabitants (as of 2010, Agência Nacional de Telecomunicações [ANATEL], n.d.), the Brazilian mobile telephony market - a third of the Latin American market and the sixth-largest national market in the world (Central Intelligence Agency [CIA], n.d.) - recently reached its maturity stage (characterized by 100 or more lines per 100 inhabitants; ANATEL, n.d.). The latest regulatory change in the mobile phone industry, the implementation of cell phone number portability when switching carriers (as of March 2009), sought to reduce barriers to switching service providers.

In the early stages of market growth, the wireless industry players in Brazil bet on winning new customers. But, as the market advanced and became more crowded with rivals, the importance of retaining subscribers became the main focus. In very competitive markets, signing up new subscribers becomes more difficult and more expensive than retaining current customers, in part because the carriers already have information on the preferences and behaviors of their users, thereby facilitating the adaptation of their strategies to specific needs (Seo, Ranganathan, \& Babad, 2008). Costs associated with acquiring new subscribers, such as setting up and configuring new accounts, credit analysis, advertising, and operating expenses, can render the cost of acquiring a new subscriber five times higher than retaining a current subscriber (Farber \& Wycoff, 1991, Peters, 1988). Such arguments emphasize the importance of understanding the formation of switching intention and its dynamics in consumer behavior.

This study was conducted when the option of number portability in Brazil (in effect since March 2009) had just completed its implementation cycle. Its uniqueness lies in the comparison of two markets with different cultures - Brazil (with104 lines/100 inhabitants; ANATEL, n.d.) and Germany (129 lines/100 inhabitants; CIA, n.d.) - and in the attempt to identify similarities and differences in the formation of switching intentions between consumers from each country. Comparative marketing studies to uncover similarities and differences between different countries, which consider specific elements of their marketing systems and properties of their societal systems, such as culture, have been welcomed by scholars (Boddewyn, 1981).

The subjects consisted of residential users (who use mobile phones for non-commercial purposes) who subscribed to postpaid services. The choice is justified by the fact that, despite representing only $18.57 \%$ of total mobile phone users in Brazil, this group has an average monthly income up to seven times higher than users of prepaid services, and are the most valuable customers for carriers to retain (ANATEL, n.d.). Due to the high cost of conducting more comprehensive data collection, mobile phone service users were surveyed in just one city in each country: Rio de Janeiro in Brazil and Ingolstadt in Germany.

\section{Factors Influencing Switching Intention}

Dick and Basu (1994) defined loyalty as a strong relationship between relative individual attitudes and repeat purchases, manifesting as the proportion, sequence, and likelihood of additional purchases from the same supplier. Oliver (1996) defined it as a deep commitment to repurchase a product or service in the future, despite situational influences or marketing efforts with the potential to cause behavior change. One can assume that a low level of switching intention would be an indicator of loyalty. Given the continuous nature of mobile phone services, if the consumer does not intend to switch, the consumer's loyalty to the provider may be inferred. 
Fornell (1992) considered that loyalty is a function of consumer satisfaction and switching barriers. Switching barriers consist of discounts for loyal clients, cognitive efforts customers would make to find another supplier and financial, social and psychological risks for buyers. However, Fornell (1992) alerted that it might not be possible to determine whether satisfaction would be more effective than switching barriers to retain a customer.

Switching costs were defined by Porter (1998) as those involved in changing from one service provider to another, including not only costs that can be measured in monetary units, but also psychological effects of becoming a client of a new provider and effort and time involved in adapting to a new firm (Klemperer, 1995).

There are three kinds of switching costs - learning costs, transaction costs and contractual costs (Klemperer, 1987, 1995). Jones, Mothersbaugh and Beatty (2002) demonstrated the multidimensional nature of service switching costs, pointing out three main dimensions: continuity costs (including contractual lock-in costs that penalize a discontinued service relationship), learning costs and sunk costs (that are mostly psychological in nature).

Weiss and Anderson (1992) considered the effects of two categories of switching costs: those incurred by consumers (transaction costs and efforts to learn to use new options) and costs that would lock consumers into a service provider, such as contractual restrictions or penalties for commercial relationship termination.

While learning costs and transaction costs reflect social costs of switching providers or brands, contractual costs are an artificial type that is distinguished from the other two by the absence of the social costs of switching (Klemperer, 1987). Contractual costs are due to long-term contracts, created by firms in competitive markets in order to penalize switching by customers, to bear set-up costs that cannot be recouped by entry fees (Büschken, 2004; Caruana, 2004). Büschken (2004) called them "contractual lock-in" (p. 81).

The impact of switching costs on customer loyalty in mobile telecommunications markets was the subject of various studies. Caruana (2004) demonstrated that, for corporate customers, the higher the contractual switching costs, the stronger the customer cognitive loyalty. He also found that there is a link between relational switching cost (costs related to personal and brand relationship losses) and affective and cognitive loyalty.

Kim, Park and Jeong (2004) tested a model in the Korean market, where service performance was a function of call quality, value-added services and customer support. Switching costs involved loss cost and move-in cost. In the German mobile market, Gerpott, Rams and Schindler (2001) found that customer retention was achieved both by extending the contract over a specific time (what they called the captive customer and by customer intention to maintain a provider, refraining from quitting the contract (loyalty customer). They also showed that customer satisfaction was affected by the price charged (the customer's perception of what is good and fair), perceived personal benefits, and perceived network quality. These considerations lead to the model depicted in Figure 1, which was tested in this study.

Based on this model, Shin and Kim (2008) conducted a study of the US mobile market and found that both consumer satisfaction and switching barriers impacted intentions and attitudes to switching. A significant relationship was also found between perceived service performance and customer satisfaction, implying an indirect effect on intention to switch.

Price, understood as perceived value, did not present significant effects upon consumer satisfaction and did not seem to influence intention to switch. Satisfaction had an inverse influence on switching intention, suggesting that satisfied customers are less likely to switch than unhappy consumers. The relationships found suggest that, if consumers perceive they are getting a high-value service in relation to the rates they pay, they will tend to be satisfied and continue with their service providers, with perceived price being converted into quality of service (performance improvement) and satisfaction with the service. Switching barriers appeared to be influenced by contractual lock-in 
mechanisms created by service providers and the rising cost of switching, having an inverse influence on intention to switch (Shin \& Kim, 2008).

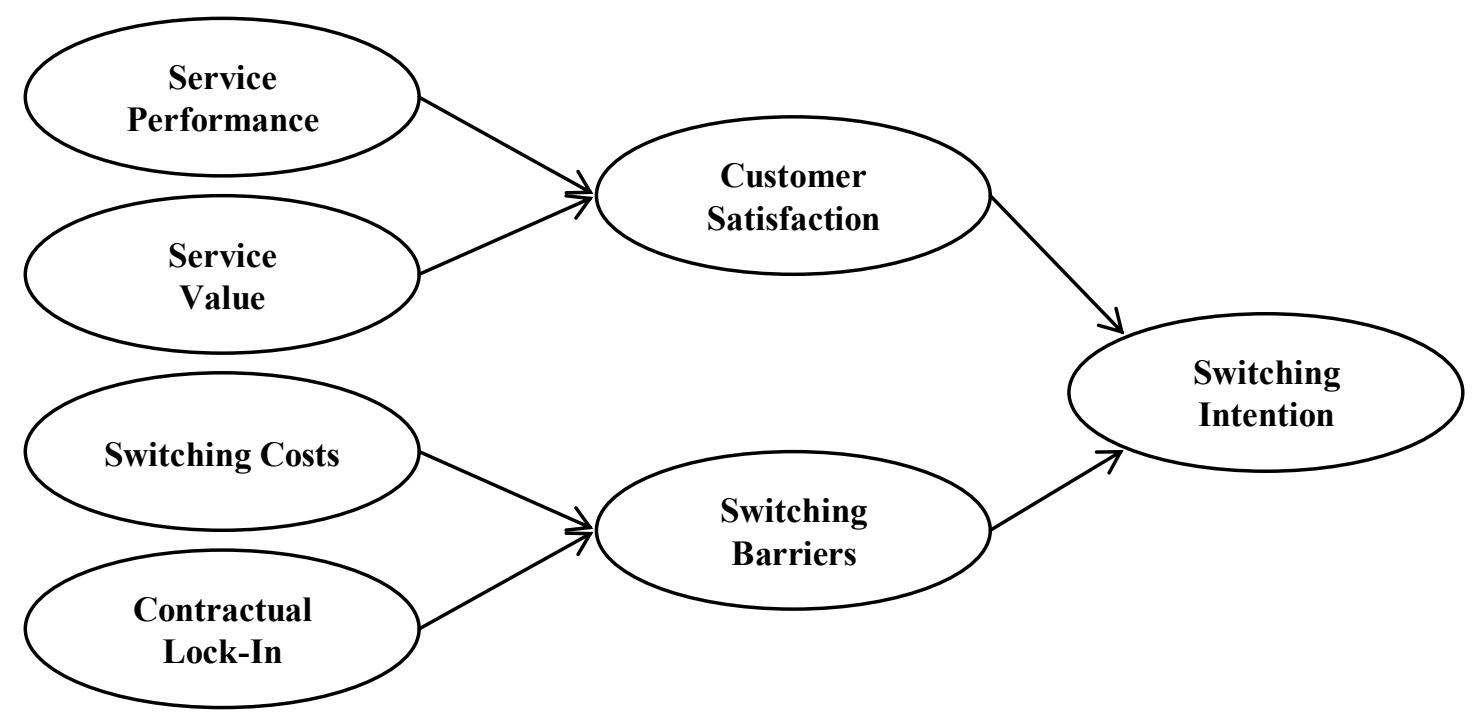

Figure 1. Factors Influencing Switching Intention.

Source: Based on Shin, D. H., \& Kim, W. Y. (2008). Forecasting customer switching intention in mobile service: an exploratory study of predictive factors in mobile number portability (p. 868). Technological Forecasting \& Social Change, 75(6), 854-874. doi: 10.1016/j.techfore.2007.05.001

\section{Cultural Differences}

Consumer behavior is directly affected by cultural factors, as well as through consequences of culture (Manrai \& Manrai, 2011). People in different countries think, feel and act differently (Hofstede, Hofstede, \& Minkov, 2010). Such patterns of thinking, feeling and acting are learned during an individual's lifetime, forming what Hofstede, Hofstede and Minkov (2010) called mental programs or culture.

Geert Hofstede developed a model to understand the differences among national cultures. Each dimension is an aspect of a culture that can be measured in relation to other cultures (Hofstede et al., 2010):

- Power distance (PDI) expresses the attitude of a culture towards inequalities amongst its members.

- Uncertainty avoidance (UAI) is the extent to which members of a society feel threatened by ambiguity or unknown situations and have developed beliefs and institutions that try to avoid these.

- Individualism (IDV) is the degree of independence a society maintains among its members.

- Masculinity (vs. femininity) (MAS) indicates that a society will be driven by competition and success (masculinity) or whose dominant values are caring for others and quality of life (femininity).

Later, a fifth dimension was incorporated, long term orientation (LTO), corresponding to the extent to which a society shows a pragmatic future-oriented perspective, rather than a conventional, historical short-term view.

Hofstede measured the scores for his suggested dimensions in many countries (Hofstede et al., 2010). Those scores allow comparisons among cultures, based on cultural distances. Table 1 presents 
Hofstede's scores for Brazil and Germany (Hofstede et al., 2010), as well as the variance in each cultural dimension (Kandogan, 2012).

Table 1

Hofstede's Cultural Dimensions Scores for Brazil and Germany

\begin{tabular}{cccc}
\hline Dimension & Variance & Brazil & Germany \\
\hline PDI & 422.0 & 69 & 35 \\
IDV & 505.6 & 38 & 67 \\
MAS & 260.4 & 49 & 66 \\
UAI & 490.2 & 76 & 65 \\
LTO & 754.8 & 65 & 31 \\
\hline
\end{tabular}

Note. Source: Hofstede, G., Hofstede, G. J., \& Minkov, M. (2010). Cultures and organizations: software of the mind (3rd ed.). New York: McGraw Hill; e Kandogan, Y. (2012). An improvement to Kogut and Singh measure of cultural distance considering the relationship among different dimensions of culture. Research in International Business and Finance, 26(2), 196-203. doi: 10.1016/j.ribaf.2011.11.001

It has been demonstrated that Hofstede's cultural dimensions are a powerful way to explain cultural differences at the country-level (Goodrich \& Mooij, 2011). They are robust and valid for applications in the evaluation of differences between national cultures related to consumer behavior (Leung, Bhagat, Buchan, Erez, \& Gibson, 2005; Magnusson, Wilson, Zdravkovic, Zhou, \& Westjohn, 2008). Yoo, Donthu and Lenartowicz (2011) considered that, when culture is used as a contextual variable (like in the present study), the use of Hofstede's indexes to examine the effect of culture on consumer behavior is a well accepted tradition that "has its benefits and would continue to be a mainstream use of the scale" (p. 195).

\section{Overview and Hypotheses Development}

Hofstede's cultural dimensions have important influence when social exchange involving service firms and their customers is considered (Matos, Fernandes, Leis, \& Trez, 2011). Studies showed that service performance is significantly related to consumer satisfaction (Gerpott, Rams, \& Schindler, 2001; Shin \& Kim, 2008).

In more masculine societies, performance is highly valued (Hofstede et al., 2010). Leng and Botelho (2010) found that, when purchasing mobile phones, consumers from more individualistic cultures are generally more quality conscious than consumers from collectivistic cultures.

German culture presents higher scores of individualism and masculinity than Brazilian culture, thus allowing proposal of the first hypothesis:

H1. German consumers will present higher positive effects of perceived service performance on customer satisfaction than Brazilian consumers.

In the mobile telephony industry, high perceived value means satisfaction with the total amount paid by the user for the combined cost of the line, voice calls and other services included in the contract (Kim, Park, \& Jeong, 2004). When consumers feel they are getting a high-value service in relation to its price, they will more likely be satisfied and will tend to remain with their current carriers (Shin \& Kim, 2008). Turel and Serenko (2006) have also demonstrated a strong correlation between perceived value and consumer satisfaction with mobile services. 
Price consciousness can be understood as a buyer's focus on paying low prices (Lichtenstein, Ridgway, \& Netemeyer, 1993). Individuals in masculine-oriented cultures emphasize ego-goals, so price-conscious decision-making will result in goods and services being purchased for less, thus allowing more items and money to be accumulated (Hofstede et al., 2010). Due to the fact that consumers in both countries have good knowledge of the prices charged for contracted services, since mobile telephony has been offered for many years and German culture presents higher scores of masculinity and individuality than Brazilian culture, it can be proposed that:

H2. German consumers will present higher positive effects of perceived service value on consumer satisfaction than Brazilian consumers.

Jones, Mothersbaugh and Beatty (2000) defined switching barriers as factors that may make it more difficult or costly to switch service providers. In the mobile phone industry, such barriers would include costs incurred in switching carriers and the effects of lock-in techniques used by carriers (Shin \& Kim, 2008). Switching costs are those involved in changing from one service provider to another (Porter, 1998), accounting for psychological effects (e.g., learning and sunk costs) and for the effort and time involved in adapting to a new firm (Klemperer, 1995).

Customers from uncertainty avoiding cultures are less tolerant of unexpected situations and unwilling to accept risks. They feel threatened by the unknown, favoring what they are used to, and tend to be hesitant toward new products or services (Hofstede et al., 2010). Brazilian and German cultures score very closely in the UAI dimension, so Brazilians should feel a level of stress similar to Germans when presented with unexpected situations or risks (Hofstede et al., 2010; Hofstede, n.d.; Leo, Bennett, \& Härtel, 2005). Hence, it is reasonable to propose that:

H3. There will be no difference between Brazilian and German consumers in relation to the positive direct effects of switching costs over switching barriers.

Fornell (1992) considered loyalty as a function of satisfaction and switching barriers. Gerpott et al. (2001) found that an increase of one unit in customer satisfaction translated to a growth of 0.75 units in loyalty to the service provider in the German mobile market.

Lim, Widdows and Park (2006) studied the relationship between satisfaction and loyalty to the supplier in the US market, obtaining results similar to those of Gerpott et al. (2001). Customer satisfaction seems to be a powerful indicator of consumer loyalty, as there is a strong positive effect between the level of customer satisfaction and the level of customer loyalty to the service provider.

Leo, Bennett and Härtel (2005) considered brand loyalty as a risk reduction strategy and, as such, it should be consistent with Hofstede's uncertainty avoidance dimension. The masculinity dimension also plays a role in loyalty formation: lower score cultures highly value quality of life and, as a consequence, tend to value satisfaction higher than more masculine cultures (Hofstede et al., 2010; Hofstede, n.d.). Given that Brazilians score higher than Germans in the UAI dimension, but lower in the MAS dimension, the fourth hypothesis can be proposed as:

H4. There will be no difference between Brazilian and German consumers in relation to the positive direct effects of customer satisfaction over switching intention.

Kim et al. (2004) identified a positive relationship between switching barriers and customer retention in the Korean mobile phone market. The relationship was also found in a study of service customers, increasing the possibility of a positive relationship between perceived barriers to switching and repurchasing intentions (Jones, Mothersbaugh, \& Beatty, 2002). It can be assumed that switching barriers would act as agents inhibiting switching among carriers, as they represent risks for switching consumers, involving risks of adapting to a new firm, risks of not getting satisfactory service and the financial risk represented by lock-in contractual penalties. High UAI scores mean unwillingness to run unfamiliar risks. High MAS corresponds to the importance for the consumer of getting visible results (Hofstede et al., 2010; Hofstede, n.d.). Given that Brazilians score higher than Germans in the UAI dimension, but lower in the MAS dimension, it is hypothesized that: 
H5. There will be no difference between Brazilian and German consumers in relation to the positive direct effects of switching barriers over switching intention.

In addition to the psychological and social costs that compose switching costs (Klemperer, 1987), financial barriers created by the imposition of longer contracts (Klemperer, 1987, 1995) and contract termination fees (Büschken, 2004) can act as resources for customer retention, even when satisfaction with the service is lacking (Lee, Kim, \& Park, 2004).

Those contractual lock-in costs are monetary penalties created to penalize switching (Büschken, 2004; Caruana, 2004), distinguished from switching costs by the absence of any social, time consuming or psychological aspect (Klemperer, 1987). Since individuals in masculine-oriented cultures are more price-conscious (Hofstede et al., 2010; Hofstede, n.d.) and given that German culture scores higher than Brazilian culture on the masculinity dimension (1.11), it can be proposed that:

H6. German consumers will present higher positive effects of contractual lock-in over switching barriers than Brazilian consumers.

\section{Method}

A survey was conducted on samples of mobile phone users in Brazil and Germany to test the proposed hypotheses. The choice of variables was based on the model presented in Figure 1, which identifies the relationships among constructs that might influence the formation of switching intention.

\section{Questionnaire design}

The initial version of the questionnaire was based on scales developed and tested in previous studies, as indicated: Service Performance (Cheong \& Park, 2005; Shin \& Kim, 2008), Service Value (adapted from Brynjolfsson \& Smith, 2000), Customer Satisfaction (based on Fornell, Johnson, Anderson, Cha, \& Bryant, 1996; Shin \& Kim, 2008), Switching Costs (Jones et al., 2002), Contractual Lock-in (Chen \& Hitt, 2002), Switching Barriers (Kim et al., 2004) and Switching Intention (Kim et al., 2004).

Since the scales were developed for use in other cultures, the first stage of the research focused on evaluating their application in different countries (Patterson \& Smith, 2003). To achieve that, Brazilian and German heavy users of mobile phone services were interviewed in-depth, in an attempt to capture additional relevant factors, as well as to fit the original indicators to both languages and cultures. Three users were interviewed in Germany and six in Brazil.

Respondents were asked to highlight service attributes related to the constructs of interest that they considered to be relevant. The interviews lasted (on average) one hour. The items were then adapted so a higher level of equivalence could be obtained. A marketing student, a native German speaker and proficient in Portuguese, translated the resulting questionnaire to German. The questionnaire was back translated to Portuguese by a Brazilian scholar, proficient in German, to ensure that the translated version had the same meaning in both languages (Hambleton, 1993). Several modifications were necessary to maintain the equivalence in both languages, since certain words and phrases had no exact equivalent in German.

The instrument was refined with the conduction of pre-tests on different small samples in both countries, totaling 102 participants. The pre-tests were conducted both on the web and in person (three pre-tests for each data collection method), resulting in the elimination of some items and re-wording others, in order to obtain the final form of the questionnaire. 
The first part of the questionnaire contained questions with transactional variables, intended to identify usage profile, and filter questions to separate the sample with respect to a user's service plan and carrier. The second part presented questions to capture the perception of respondents about the constructs of interest, measured on five-point Likert scales ranging from strongly disagree to strongly agree with the neither agree nor disagree as the central point. The third part involved demographic questions. The items that composed each construct's scale are presented in the Appendix.

\section{Sample Selection}

The two samples consisted of residential mobile telephony customers (i.e., those who utilize the service for non-commercial purposes, and who are responsible for selecting the service provider and paying the bills) who subscribed to postpaid services.

Taking into account the recommendations of Loehlin (1992), Hoyle (1995) and Kline (1998) and the number of indicators involved in the structural model proposed (28), efforts were made to obtain more than 200 valid questionnaires in each of the countries evaluated (Brazil and Germany). Due to restrictions related to cost and time, convenience sampling was employed.

\section{Procedures for data collection}

Data collection occurred during the months of March and April 2009, on a temporary website created to host the research instrument. A link to the website was sent via e-mail to undergraduate and graduate student discussion groups in Brazil (Rio de Janeiro) and Germany (Ingolstadt).

Two hundred fifty six questionnaires were obtained in Brazil, 235 of which were valid (91.8\%). Questionnaires that presented the pre-paid option as a response to the question about the type of plan (12 questionnaires), business line paid by the company (11) and others (2) were discarded. After discarding those responses, 202 valid questionnaires remained.

In Germany, 263 questionnaires were obtained, of which 239 (90.8\%) were complete. After discarding questionnaires involving plans not included in the sample criteria (pre-paid $=29$; business line paid by the company $=9$, others $=1$ ), 200 questionnaires were considered for further analysis.

\section{Data Analysis}

\section{Sample description}

In the Brazilian sample, $57 \%$ of respondents had been customers of the current carrier for more than four years and $40 \%$ spent, on mobile services, more than $\mathrm{R} \$ 151.00$ (€65) per month (which would be equivalent to around $22 \%$ of the Brazilian minimum monthly wage of R $\$ 678,00$ ). Also, $49 \%$ of respondents had never switched carriers and $53 \%$ had their current handset for less than one year; while $75 \%$ of respondents were using up to two extra services (messaging, Internet, email, or content downloads). Demographic data indicated that $56 \%$ of the sample were women and $40 \%$ had a monthly income exceeding $\mathrm{R} \$ 5,501.00(€ 2,400.00)$. Over $80 \%$ of respondents reported having been educated to at least college level.

In the German sample, $48 \%$ of respondents were customers of the largest carrier in the market, $36 \%$ had been customers of the current carrier for over four years and $81 \%$ spent up to $€ 40$ per month on mobile telephony (which would be equivalent to around 3\% of the German minimum monthly wage of $€ 1200,00)$. It was also detected that $42 \%$ of respondents had acquired the current handset 
within the last year, $48 \%$ had switched carrier at least once and $84 \%$ were using up to two additional services. Among German respondents, demographic data indicated that 50.5\% were men, $90 \%$ were educated at least to college level and $45 \%$ had a household monthly income above $€ 5,000.00$.

\section{Measurement equivalence}

Multiple-group confirmatory factor analysis was used to test the cross-cultural invariance and the various hypotheses regarding the differences in perceptions between Brazil and Germany (Byrne, 2010). As a first step, multiple-group models without constraints on the parameters were estimated simultaneously, to test if the same model form held across groups. The next stage involved a comparison of the unconstrained model with a constrained one, in which equality constraints were imposed across the two samples. In this case, if the fit of the unconstrained model does not differ significantly from the fit of the constrained one, it can be said that the factor structure is similar across samples (Byrne, 2010; Durvasula, Andrews, Lysonski, \& Netemeyer, 1993). The obtained results, as subsequently shown, indicate similarity in the fit of the unconstrained and constrained models, pointing towards invariant factor structures across the two samples.

In cross-cultural research, it is important to establish data equivalence to allow correct interpretation and execution of cross-cultural comparisons. Measurement equivalence assesses if the same model holds when tested in different cultures (Mullen, 1995; Steenkamp \& Baumgartner, 1998). The three most important types of measurement equivalence are translation equivalence, sample equivalence and metric equivalence (Sin, Cheung, \& Lee, 1999). Translation equivalence seeks to guarantee that all items in the translated versions of the research instrument have the same meaning. This is often satisfied with the employment of back-translation procedures (Hult et al., 2008), as was done in this study. Sample equivalence evaluates to which extent the samples collected from different cultures are comparable (Mullen, 1995), so that any observed cross-cultural difference is a result of actual discrepancy between cultural groups and not a result of samples with heterogeneous characteristics. According to Sin, Cheung and Lee (1999), sample equivalence can be achieved by the usage of similar sampling methods and groups in all cultures evaluated. Since the same sampling method was employed to collect data in Brazil and Germany, targeting in both countries a homogenous group of undergraduate and graduate students of a single city and university, with similar demographic statistics, sample equivalence was enhanced in this study. Finally, metric equivalence tests if the psychometric properties of data from different cultures possess the same coherence and structure (Hult et al., 2008). By satisfying metric equivalence, interpretation and conclusions regarding cultural differences should be affected by measure unreliability or differing dimensionality. Metric equivalence for the Brazilian and German samples was evaluated via multiple-group confirmatory factor analysis (CFA) (Byrne, 2010), as detailed ahead.

\section{The measurement model}

Confirmatory factor analysis (CFA) was conducted to test the validity, unidimensionality, reliability and metric equivalence of the scales used in the measurement model. A few items with squared multiple correlations lower than 0.3 were dropped, in an effort to find a model with satisfactory fit (Byrne, 2010). The same items were dropped from all samples, ensuring equivalence across countries. The final number of indicators per construct, as well as their composite reliabilities and variance extracted measures are presented in Table 2, while their complete descriptions can be found in the Appendix, where the items dropped from the analysis are indicated by $(*)$. Even though two constructs ended up with only two indicators in the final measurement model (Contractual LockIn and Switching Barriers), the model had 462 distinct sample moments and only 126 parameters to be estimated, resulting in enough degrees of freedom (336) to guarantee over identification and allow estimation, albeit having three or more indicators per construct would still have been desired (Hair, Black, Babin, \& Anderson, 2009). As can be observed, all composite reliabilities were above 0.7 and all measures of variance extracted were above 0.5 , indicating reliability of the employed constructs (Byrne, 2010). 
Table 2

Construct Reliability Analysis

\begin{tabular}{lccccc}
\hline & & \multicolumn{2}{c}{ Composite Reliability } & \multicolumn{2}{c}{ Variance Extracted } \\
\cline { 3 - 6 } \multicolumn{1}{c}{ Construct } & No. of Items & Brazil & Germany & Brazil & Germany \\
\hline Service Value & 3 & 0.79 & 0.76 & 0.67 & 0.69 \\
Service Performance & 3 & 0.82 & 0.76 & 0.71 & 0.69 \\
Switching Cost & 3 & 0.79 & 0.77 & 0.77 & 0.76 \\
Contractual Lock In & 2 & 0.75 & 0.70 & 0.69 & 0.51 \\
Customer Satisfaction & 5 & 0.78 & 0.83 & 0.73 & 0.80 \\
Switching Barrier & 2 & 0.76 & 0.79 & 0.74 & 0.75 \\
Switching Intention & 3 & 0.83 & 0.89 & 0.82 & 0.89 \\
\hline
\end{tabular}

Based on the measurement models, procedures were performed to test nomological validity (analysis of the correlation matrix between constructs); convergent validity (calculation of Average Variance Extracted [AVE] for each construct); discriminant validity (comparison of the average variance extracted for each construct with shared variance - the square of correlation coefficient between all pairs of constructs, as presented on Tables 3 and 4); internal consistency and unidimensionality. The results were satisfactory, indicating that the scales are reliable for both samples.

Table 3

Correlation and Discriminant Validity Matrix (Brazil)*

\begin{tabular}{cccccccc}
\hline & SV & SP & SC & CL & CS & SB & IS \\
\hline SV & $\mathbf{0 . 6 7}$ & 0.77 & 0.25 & -0.45 & 0.78 & -0.29 & -0.64 \\
SP & 0.59 & $\mathbf{0 . 7 1}$ & -0.25 & -0.34 & 0.83 & -0.25 & -0.63 \\
SC & 0.06 & 0.06 & $\mathbf{0 . 7 7}$ & 0.33 & -0.23 & 0.85 & -0.11 \\
CL & 0.20 & 0.12 & 0.11 & $\mathbf{0 . 6 9}$ & -0.37 & 0.39 & 0.31 \\
CS & 0.61 & 0.69 & 0.05 & 0.14 & $\mathbf{0 . 7 3}$ & -0.19 & -0.72 \\
SB & 0.08 & 0.06 & 0.72 & 0.15 & 0.04 & $\mathbf{0 . 7 4}$ & -0.07 \\
IS & 0.41 & 0.40 & 0.01 & 0.10 & 0.52 & 0.00 & $\mathbf{0 . 8 2}$ \\
\hline
\end{tabular}

Note. Correlations are above the main diagonal, Squared Correlations are below.

* SV = Service Value, $\mathrm{SP}=$ Service Performance, $\mathrm{SC}=$ Switching Cost, $\mathrm{CL}=$ Contractual Lock In, CS $=$ Customer Satisfaction, $\mathrm{SB}=$ Switching Barrier, SI = Switching Intention 
Table 4

Correlation and Discriminant Validity Matrix (Germany)*

\begin{tabular}{cccccccc}
\hline & SV & SP & SC & CL & CS & SB & IS \\
\hline SV & $\mathbf{0 . 6 9}$ & 0.78 & 0.03 & -0.02 & 0.82 & -0.12 & -0.68 \\
SP & 0.61 & $\mathbf{0 . 6 9}$ & -0.04 & -0.06 & 0.81 & -0.08 & -0.61 \\
SC & 0.00 & 0.00 & $\mathbf{0 . 7 6}$ & 0.46 & -0.05 & 0.86 & -0.03 \\
CL & 0.00 & 0.00 & 0.21 & $\mathbf{0 . 5 1}$ & -0.04 & 0.54 & 0.09 \\
CS & 0.67 & 0.66 & 0.00 & 0.00 & $\mathbf{0 . 8 0}$ & -0.01 & -0.82 \\
SB & 0.01 & 0.01 & 0.74 & 0.29 & 0.00 & $\mathbf{0 . 7 5}$ & -0.06 \\
IS & 0.46 & 0.37 & 0.00 & 0.01 & 0.67 & 0.00 & $\mathbf{0 . 8 9}$ \\
\hline
\end{tabular}

Note. Correlations are above the main diagonal, Squared Correlations are below.

* SV $=$ Service Value, $\mathrm{SP}=$ Service Performance, $\mathrm{SC}=$ Switching Cost, $\mathrm{CL}=$ Contractual Lock In, CS $=$ Customer Satisfaction, $\mathrm{SB}=$ Switching Barrier, $\mathrm{SI}=$ Switching Intention

Two sets of measurement models were tested (Bollen, 1989), one containing exogenous variables and the other built with the endogenous constructs. For both exogenous and endogenous parts of the model, $\chi^{2} /$ df. measures were below 3.0, while the comparative fit index (CFI), the incremental fit index (IFI) and the Tucker-Lewis index (TLI) measures were above 0.9 (Byrne, 2010). The root mean-squared error of approximation (RMSEA) values were between 0.04 and 0.06 , indicating a good fit along with root mean square residual (RMR) values below 0.08 (L.-T. Hu \& Bentler, 1998). These satisfactory fit indices were observed in both samples.

Using a nested testing hierarchy, as proposed by Bollen (1989), a multiple-group CFA was performed to evaluate the cross-national invariance of the research instrument. Table 5 presents the obtained fit indices. The unconstrained model (Model 1), where no constraints were placed across groups, was tested first. Model 1 presented good fit indices, within the range of those recommended by the literature (Byrne, 2010), both for the exogenous and the endogenous parts, indicating that the form of the measurement models were adequate for both samples.

Table 5

Fit Indices of Multiple-group CFA Analysis for Measurement Models

\begin{tabular}{ccccc}
\cline { 2 - 5 } & \multicolumn{2}{c}{ Exogenous } & \multicolumn{2}{c}{ Endogenous } \\
\hline Fit Index & Model 1 & Model 2 & Model 1 & Model 2 \\
\hline$\chi 2$ & 124,23 & 154,98 & 181.64 & 194.33 \\
df & 76 & 83 & 64 & 71 \\
$\chi 2$ df. & 1.64 & 1.86 & 2.81 & 2.74 \\
RMSEA & 0.04 & 0.04 & 0.05 & 0.06 \\
RMR & 0.07 & 0.08 & 0.06 & 0.08 \\
TLI & 0.94 & 0.93 & 0.92 & 0.93 \\
IFI & 0.96 & 0.94 & 0.95 & 0.94 \\
CFI & 0.958 & 0.954 & 0.946 & 0.942
\end{tabular}

Note. Model 1: Unconstrained model. Model 2: Factor loadings are constrained to be equal. 
The next step involved the comparison of the unconstrained model (Model 1) with a constrained one (Model 2), in which the factor loadings were constrained to be invariant across samples (Bollen, 1989). The differences of $\chi^{2}$ between Model 2 and Model 1 for the exogenous was significant $\left(\Delta \chi 2_{\text {Exogenous }}=30,75, \Delta \mathrm{df}=7, \mathrm{p}<0,001\right)$, whereas it was not significant for the endogenous part $\left(\Delta \chi 2_{\text {Endogenous }}=12,69, \Delta \mathrm{df}=7, \mathrm{p}=0,08\right)$, indicating invariance for the endogenous part of the model. Nevertheless, Byrne (2010) suggests the evaluation of the differences in CFI between models ( $\triangle \mathrm{CFI}$ ), given that $\chi 2$ difference tests can be particularly rigid. Cheung and Rensvold (2002), after a thorough Monte Carlo study testing different goodness-of-fit indices, suggested that evidence of invariance between models could be garnered via the difference in CFIs. The $\triangle$ CFI between Model 1 and Model 2 , both for the exogenous and endogenous parts, were under 0.005 , which is below the threshold level of 0.01 recommended by Byrne (2010). This result indicates that factor loadings were invariant across the two samples.

\section{The structural model}

Having ascertained measurement invariance across samples, the structural model was tested. Multiple-group structural equation modeling (SEM) was also employed at this stage, to evaluate whether the magnitude of the relationships among constructs held across countries. Table 6 presents the results for this test, where the unconstrained model (Model 1), in which data from the two groups were analyzed simultaneously with no constraints imposed, was compared to a constrained model (Model 2), in which all the structural paths were imposed to be equal across the two samples (Byrne, 2010).

Table 6

Fit Indices of Multiple-group SEM Analysis for Structural Model

\begin{tabular}{ccc}
\hline Fit Index & Model 1 & Model 2 \\
\hline$\chi^{2}$ & 649,75 & 694,81 \\
$\mathrm{df}$ & 354 & 374 \\
$\chi 2 / \mathrm{df}$ & 1.83 & 1.86 \\
RMSEA & 0.04 & 0.04 \\
SRMR & 0.05 & 0.06 \\
TLI & 0.92 & 0.91 \\
IFI & 0.93 & 0.92 \\
CFI & 0.93 & 0.92 \\
\hline
\end{tabular}

Note. Model 1: Unconstrained model. Model 2: Structural paths are constrained to be equal.

All fit indices for both models fall within the recommended values, indicating that the same structural model form applies to both countries. Furthermore, the $\Delta$ CFI of 0.01 between Model 1 and Model 2 supports the idea that the structural paths are invariant across the two countries, presenting evidence that no significant differences could be found between the two countries in regard to the evaluated relationships.

The model fitted to the data obtained from Brazilian consumers accounted for $76 \%$ of the explained variance for customer satisfaction, $80 \%$ for barriers to switching and $52 \%$ for switching intention. These results suggest that, despite the satisfactory explanatory power for the first two constructs, it is likely that there are other factors that contribute to the formation of switching intention. 
Better results were obtained with data from the German sample. For customer satisfaction, the degree of explanation was $84 \%$, suggesting that the indicators that form the construct are able to capture most of the component attributes. For switching barriers, degree of explanation was $81 \%$, well above the original model $(52 \%)$. For switching intention, the value was $62 \%$; this value is higher than in the Brazilian sample (52\%). Similar to the Brazilian result, this figure suggests that, possibly, other indicators not included in the study must contribute to the construct.

\section{Hypotheses testing}

In structural equation modeling, the significance of the estimated coefficients for the relationships present in the model indicates whether each hypothesized relationship among constructs holds true or not (Byrne, 2010). Given that standardized coefficients are sample specific and not comparable across samples, unstandardized coefficients were used to discuss the results, since they are comparable across samples and retain their scale effect (Byrne, 2010). For the two samples, the estimated unstandardized coefficients, along with their significance, are presented in Table 7.

Table 7

Estimated Unstandardized Coefficients and Significance

\begin{tabular}{lcccc} 
& \multicolumn{2}{c}{ Brazil } & \multicolumn{2}{c}{ Germany } \\
\cline { 2 - 5 } Path & Estimate & Sig. & Estimate & Sig. \\
\hline Service Performance $\rightarrow$ Satisfaction & 0.96 & $<0.001$ & 0.41 & 0.003 \\
Service Value $\rightarrow$ Satisfaction & 0.29 & 0.038 & 0.63 & $<0.001$ \\
Switching Cost $\rightarrow$ Switching Barriers & 0.84 & $<0.001$ & 0.70 & $<0.001$ \\
Satisfaction $\rightarrow$ Switching Intention & -1.14 & $<0.001$ & -1.32 & $<0.001$ \\
Switching Barriers $\rightarrow$ Switching Intention & 0.08 & 0.221 & 0.05 & 0.460 \\
Lock-In $\rightarrow$ Switching Barriers & 0.114 & 0.177 & 0.39 & 0,099 \\
\hline
\end{tabular}

\section{Effects Observed in the Brazilian Sample}

The results indicate that consumer satisfaction is the construct with the greatest impact on the formation of switching intention, with a total effect of -1.14 , suggesting that a one point increase in consumer satisfaction leads to a 1.14 point decrease in switching intention. This effect suggests a direct association of consumer satisfaction with switching intention.

The construct perceived service performance shows the second largest influence on the formation of switching intention, with an indirect effect via customer satisfaction. Considering the strong direct impact (0.96) on the formation of consumer satisfaction, there is a total effect on switching intention of -1.07 , a result which indicates that increased perceived quality in turn increases customer satisfaction, thus reducing switching intention.

In regard to the effect of perceived service value over customer satisfaction, the model indicates a significant causal relation between the two constructs $(0.29)$. The results confirm that a decrease in switching intention, albeit small, is expected when users perceive increased service received in relation to the amount paid, or reduction in price while maintaining the same level of service.

Despite the high explanatory level of the variable switching barriers, the construct failed to show a significant relationship with switching intention. The results indicated that, although present, 
switching barriers do not act directly on consumers' formation of switching intentions. Switching costs have a strong direct impact on the perception of such barriers, as evidenced by a coefficient of 0.84 for the direct relationship. The effects of contractual lock-in on the perception of switching barriers could not be confirmed: the relationship found was not significant.

\section{Effects Observed in the German Sample}

Regarding direct, indirect and total effects, it can be seen that, just as in the Brazilian results, customer satisfaction is the construct with the greatest influence on switching intentions (-1.32). Similarly to the Brazilian model, the increase (decrease) of one point in customer satisfaction would cause a decrease (increase) of 1.32 points in switching intention.

The construct perceived service value showed a strong indirect influence on the formation of switching intention, with a total effect of -0.83 . This result seems to stem from the relationship that perceived service value has on consumer satisfaction (unstandardized coefficient $=0.63$ ). Perceived service performance also showed significant influence on customer satisfaction. It seems to have a moderate indirect effect, via customer satisfaction, on switching intention $(-0.54)$.

Similarly to the Brazilian results, switching barriers showed no significant relationship towards the formation of switching intention in Germany. This result is at odds with studies in the literature, but was consistent in both countries. Switching barriers seem to be influenced both by the switching costs and by contractual lock-in. The results indicate a strong influence of switching costs in the formation of switching barriers (unstandardized coefficient $=0.70, p<0.001$ ). The German sample also exhibited no significant relationship between contractual lock-in and switching barriers (unstandardized coefficient $=0.39, \mathrm{p}=0.099$ )

Figure 2 illustrates the final model, showing the unstandardized estimates and their significance for both samples (Brazilian unstandardized coefficients are indicated first, with German coefficients shown below, in bold).

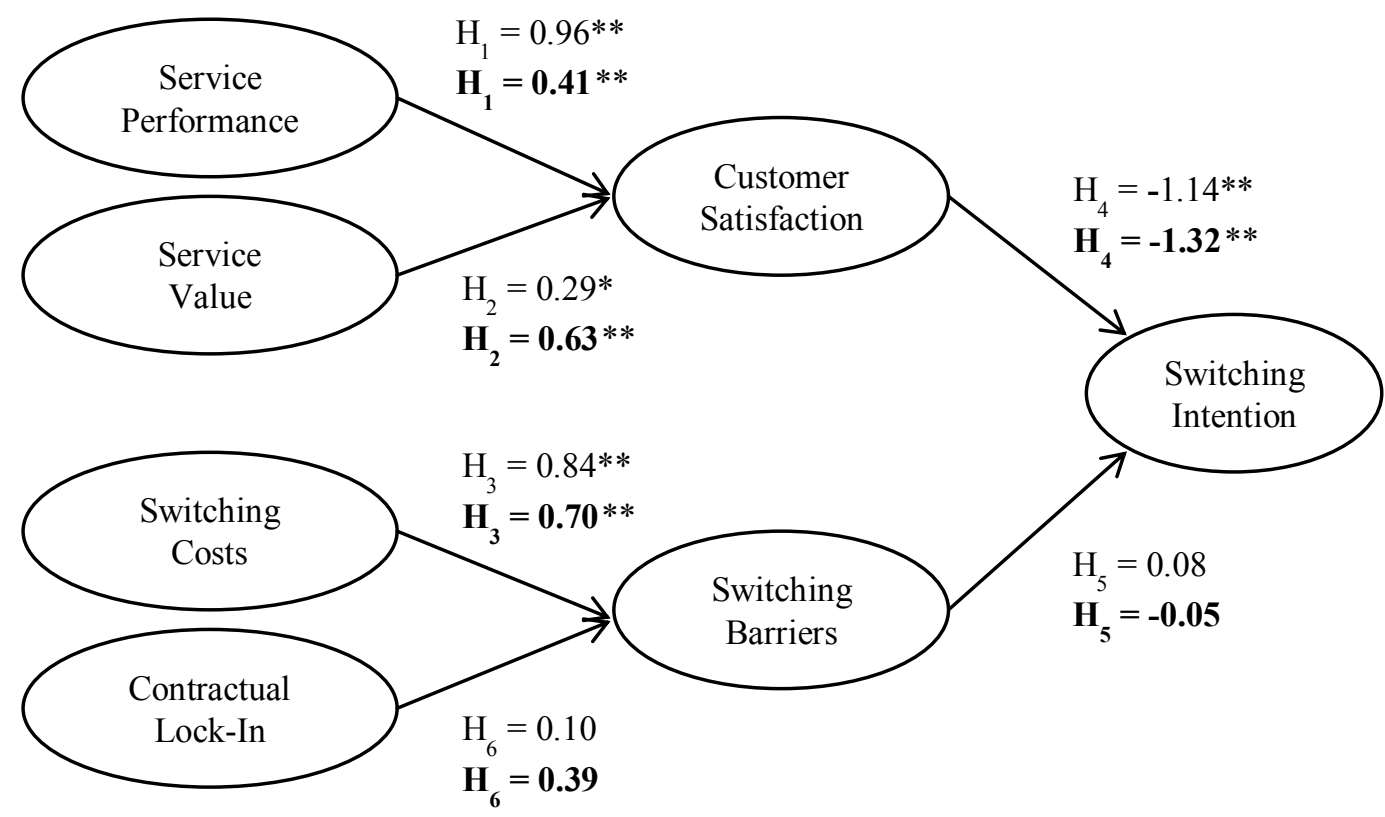

Figure 2. Estimated Unstandardized Coefficients.

$* \mathrm{p}<.05 ; * * \mathrm{p}<.01 ;$ n.s. $=$ not significant 


\section{Differences between Users' Perceptions}

Since measurement equivalence was established, it is possible to compare the estimated unstandardized coefficients for each sample to identify whether the effects of the constructs perceived service performance, perceived service value, perception of contractual lock-in, switching costs and switching barriers differed between Brazilian and German respondents. Table 8 shows the estimated unstandardized coefficients for each sample, together with the $95 \%$ inferential confidence intervals for the estimates.

According to Goldstein and Healy (1995) and further reinforced by Tyron (2001), establishing a descriptive $95 \%$ confidence interval between two means and concluding that the means differ if such intervals do not overlap does not statistically guarantee that a significant difference exists. Therefore, as Tyron (2001) proposes based on the work of Goldstein and Healy (1995), the creation of a corrected inferential confidence interval about each mean is needed in order to allow one to statistically differ two estimates or even to check if they are equivalent or if a relationship cannot be determined. In the calculation of this inferential interval, Tyron (2001) defines that a ratio of the standard error of the difference between two groups to the sum of the standard errors of both groups must be employed and multiplied to the probability level ( $\mathrm{t}_{\text {alpha }}$ ) of the corresponding $\mathrm{t}$-distribution and alpha level set for each problem.

Hence, in this paper, with the choice of a significance level of 5\% and standard errors estimated for each of the unstandardized coefficients, the inferential confidence intervals for the estimates (Table 8) were calculated with t-levels adjusted by factors that ranged from 0.707 to 0.078 , resulting in smaller confidence intervals that would have been obtained if descriptive, but inconclusive, confidence intervals were used (a reduction of around 39\% of the interval sizes, as suggested by Goldstein \& Healy, 1995). Thus, by comparing the calculated inferential confidence intervals for the relationship coefficients estimated by the multi-group structural model, statistical differences between Brazil and Germany can be assessed (Tyron, 2001). Gardner and Altman (1986) also argue that, when possible, the presentation and use of confidence intervals to test hypothesis should be preferred over the use of p-values, since it presents much more informative data than plain p-values, showing the range of values that each estimate might take.

Table 8

Inferential 95\% Confidence Intervals for the Estimated Unstandardized Coefficients

\begin{tabular}{ccccccc} 
& \multicolumn{3}{c}{ Brazil } & \multicolumn{3}{c}{ Germany } \\
\cline { 2 - 7 } Hypothesis & $\begin{array}{c}\text { Unstandardized } \\
\text { Coefficient }\end{array}$ & Low & High & $\begin{array}{c}\text { Unstandardized } \\
\text { Coefficient }\end{array}$ & Low & High \\
\hline H1 & 0.96 & 0,69 & 1,23 & 0.41 & 0,16 & 0,66 \\
H2 & 0.29 & 0,07 & 0,51 & 0.63 & 0,43 & 0,83 \\
H3 & 0.84 & 0,73 & 0,95 & 0.70 & 0,58 & 0,82 \\
H4 & -1.14 & $-1,31$ & $-0,97$ & -1.32 & $-1,49$ & $-1,15$ \\
H5 & 0.08 & $-0,01$ & 0,17 & 0.05 & $-0,05$ & 0,15 \\
H6 & 0.114 & $-0,02$ & 0,24 & 0.39 & $-0,02$ & 0,76 \\
\hline
\end{tabular}

As Table 8 shows, almost all of the calculated inferential confidence intervals for each estimate in both countries overlap, indicating that the sample results only allow for the verification of significant differences between countries in regard to the effect of service performance upon customer 
satisfaction (H1). In this particular case, the direct effect of service performance on satisfaction is seen as significantly higher in Brazil (going from 0.69 to 1.23) than in Germany (where it can be as low as 0.16 or as high as 0.66 ). Even though Leng and Botelho (2010) showed that consumers from more masculine and individualistic cultures (such as Germany) should place more importance on performance than consumers from other cultures, the results obtained here indicate that Brazilians actually place significantly more importance on the performance of their wireless services than Germans. Maybe the reason behind this happening resides in the fact that carrier connection and service issues happen more frequently in Brazil than in Germany due to the size of the country, regulations and investment in network quality by competing players. Thus, given that Brazilians are more prone to encounter poorer service performance and greater variance of service among carriers, it might be understandable that they attribute more importance to service performance than Germans, who enjoy more homogeneous high quality service from their home country carriers.

Besides the difference of the effect of service performance over satisfaction, the rest of the obtained results failed to reject the remaining null hypotheses (Cortina \& Dunlap, 1997; Cortina \& Folger, 1998). Given that, it can be said that that the collected sample does not provide enough evidence to verify any significant difference between Brazilian and German consumers in relation to the other proposed constructs, pointing towards statistical indeterminancy (Tyron, 2001).

The concept of cultural distance may provide a possible explanation for the results here obtained. Kogut and Singh (1988) proposed a way to calculate the distance between cultures, taking the relevant cultural dimensions (Hofstede's) into account, thus allowing the comparison of distances between two cultures when more than a cultural dimension is involved. It represents the relative distance of cultures from each other in the multidimensional space defined by the considered cultural dimensions, indicating the degree of similarity or dissimilarity between them.

Instead of using the Euclidean distance, Kogut and Singh proposed the use of a statistical distance, corrected for differences in the variance of each dimension and then averaged. The expression for the cultural distance is (Kogut \& Singh, 1988):

$$
\mathrm{CD}_{j}=\sum_{i=1}^{n}\left\{\left(\mathrm{Iij}_{\mathrm{ij}}-\mathrm{I}_{\mathrm{iu}}\right)^{2} / \mathrm{V}_{\mathrm{i}}\right\} / \mathrm{n}
$$

where $\mathrm{CD}_{j}$ is the cultural difference of the $j$ th country from the $u$ th country, $\mathrm{I}_{i j}$ is Hofstede's score for the $i$ th cultural dimension and the $j$ th country, $\mathrm{I}_{i u}$ the Hofstede's score for the $i$ th cultural dimension and $u$ th country, $\mathrm{V}_{i}$ the variance of the index on the $i$ th dimension, and $n$ the number of cultural dimensions.

Albeit criticized (Kandogan, 2012), the Kogut-Singh (KS) cultural distance has been employed to compare cultures in several studies (Drogendijk \& Holm, 2012; Drogendijk \& Slangen, 2006; Ng, Lee, \& Soutar, 2007).

While the KS index for cultural distance (considering Hofstede's four original dimensions) can, theoretically, range from 0 (lowest cultural distance) to 25.57 (highest cultural distance), using the countries listed in Hofstede et al. (2010) produced a range from 0.01 (Australia and USA - the two countries most culturally similar) to 10.42 (Japan and Sweden - the two countries most culturally different) (Ng et al., 2007). The cultural distance between Brazil and Germany is 1.44.

For each hypothesis, the cultural distance between the two cultures was calculated considering the dimensions involved (Table 9). In all cases, the distance is small, considering the range of 10.41 (the relatively small distance between Brazil and Germany can also be observed in the study conducted by Kandogan, 2012). The largest distance corresponds to the hypothesis where a difference was observed (H1). 
Table 9

Hypotheses, Cultural Dimensions and Cultural Distance

\begin{tabular}{ccc}
\hline Hypothesis & Dimensions involved & Cultural distance \\
\hline H1 & MAS, IND & 1.39 \\
H2 & MAS & 1.11 \\
H3 & UAI & 0.25 \\
H4 & UAI, MAS & 0.68 \\
H5 & UAI, MAS & 0.68 \\
H6 & MAS & 1.11 \\
\hline
\end{tabular}

This may suggest that the two cultures are sufficiently similar (considering the sample and the variables involved in the model) to not present differences in the studied consumer behavior, except for the effect of service performance upon satisfaction. Even in this case, it is possible that other factors, as already pointed out, could be responsible for the observed result.

\section{Conclusions}

At first glance, the results seem to contradict some of the findings by Leng and Botelho (2010). However, there is an aspect in their study that deserves attention: Hofstede et al. (2010) have pointed out that, along with individualism, the masculinity and uncertainty avoidance dimensions play a role in the use of information and communication technologies (products and services). Leng and Botelho considered only the dimensions individualism and masculinity to explain consumers' decision-making styles regarding the purchase of a mobile phone.

Although the cultural distance index (KS) between Brazil and Germany is 1.44, when the dimension power distance (not relevant for the model here employed) is not considered, the distance drops to 1.01. It seems that the large social differences observed in Brazil and captured by the power distance score inflate the overall cultural distance. However, as far as the choice of communication and technological product and services is concerned, Brazilian and German consumers show similarity in their decision-making process, given that no difference could be observed regarding the factors that could affect the decision to switch mobile phone providers.

For decisions where only the cultural dimensions of uncertainty avoidance and masculinity are involved, the cultural distance index between the two countries drops even more (0.68), suggesting greater similarity between German and Brazilian consumers' decision-making styles.

Even though differences could not be detected, the results show that customer satisfaction seems to have an inverse relationship with switching intention in both Brazil and Germany, with this factor wielding the greatest total effects on intention to switch carriers. The result can be construed as evidence that, in both countries, dissatisfied users are more likely to switch carriers, a finding consistent with those of Gerpott et al. (2001). Customer satisfaction has as antecedents the perceived service value and the perceived performance of service. In both countries, the effects of the two antecedents of satisfaction were significant, in agreement with the findings of Turel and Serenko (2006).

The results do not allow one to say that switching barriers influence the formation of switching intention, thus contradicting the findings of Shin and Kim (2008), Shin (2006) and A. W. Hu and Hwang (2006), who found inverse relationships between switching barriers and switching intention. On the other hand, Aydin, Özer and Arasil (2005) found, under certain conditions, no relation between 
the constructs. One possible explanation for this discrepancy may be the cultural distances of the markets where this work and where the other studies in the literature were conducted, which might lead to significantly different consumer decision-making behavior.

In relation to the antecedents of switching barriers, the results indicate that, for users in both countries, switching costs significantly impacted switching barriers, which seems to agree with what is expected of regulators' efforts to increase competitiveness by reducing switching costs, as is the case of the introduction of number portability in both Germany and Brazil (Turel \& Serenko, 2006). On the other hand, contractual lock-in perceptions did not present any significant impact on switching barriers in either country, which might indicate that carriers in neither of the countries are enforcing high contract termination fees or, more likely, that consumers are not aware of such contractual hindrances and, thus, do not see their current contracts as a barrier to switch carrier. Moreover, the effects of switching barriers over switching intentions were not found to be significant in either country, contradicting the findings of Kim et al. (2004) and Jones et al. (2002). This outcome possibly indicates that the sample of young university students that was collected in both countries, differently than what was expected by the literature, does not recognize any meaningful barrier to choosing another wireless service provider, deciding such change based on the satisfaction with the current service provider. The strong negative relationship between customer satisfaction and switching intention supports the results presented by Gerpott et al. (2001) and Lim et al. (2006).

\section{Limitations and suggestions for future research}

One limitation of the method concerns the sampling technique employed. Since the data were collected through a website questionnaire, whose link was sent by e-mail to students in only two cities (one in each country), the external validity of the research may be compromised (Boddewyn, 1981). Self-selection of the sample would be another drawback. A larger and representative (Boddewyn, 1981) sample would therefore be recommended. Because of this fact, and considering that cultural aspects are not the same to every individual in a culture, it is not possible to state that the relationships identified can be generalized to the two countries' populations.

Another limitation of the study resides on the fact that only two countries (Brazil and Germany) were evaluated. Therefore, all the moderating effects of culture upon the relationships that were found are restricted to consumers on these two countries and cannot be generalized, without further research, to other countries.

Given the complexity of the model and the number of indicators present, a larger sample would also minimize any problems stemming from non-normality and outliers. Furthermore, it would be interesting to assess the moderating influence that socioeconomic, regulatory, socio-demographic and relational factors may have on the formation of switching intention.

\section{References}

Agência Nacional de Telecomunicações. (n.d.). Números do setor. Retrieved from http://www.anatel.gov.br/Portal/exibirPortalInternet.do

Aydin, S., Özer, G., \& Arasil, O. (2005). Customer loyalty and the effect of switching costs as a moderator variable: a case in the Turkish mobile phone market. Marketing Intelligence \& Planning, 23(1), 89-103. doi: 10.1108/02634500510577492

Boddewyn, J. J. (1981). Comparative marketing: the first twenty-five years. Journal of International Business Studies, 12(1), 61-79. doi: 10.1057/palgrave.jibs.8490571

Bollen, K. A. (1989). Structural equations with latent variables. New York: Wiley. 
Brynjolfsson, E., \& Smith, M. (2000). Frictionless commerce? A comparison of internet and conventional retailers. Management Science, 46(4), 563-585. doi: 10.1287/mnsc.46.4.563.12061

Büschken, J. (2004). Higher profits through customer lock-in. Mason: Thomson.

Byrne, B. M. (2010). Structural equation modeling with AMOS: basic concepts, applications and programming. New York: Routledge.

Caruana, A. (2004). The impact of switching costs on customer loyalty: a study among corporate customers of mobile telephony. Journal of Targeting, Measurement and Analysis for Marketing, 12(3), 256-268. doi: 10.1057/palgrave.jt.5740113

Central Intelligence Agency. (n.d.). The world factbook. Welcome to the world factbook. Retrieved from https://www.cia.gov/library/publications/the-world-factbook/index.html

Chen, P., \& Hitt, L. (2002). Measuring switching costs and the determinants of customer retention in internet-enabled businesses: a study of the online brokerage industry. Information Systems Research, 13(3), 255-274. doi: 10.1287/isre.13.3.255.78

Cheong, J. H., \& Park, M.-C. (2005). Mobile internet acceptance in Korea. Internet Research, 15(2), 125-140. doi: 10.1108/10662240510590324

Cheung, G. W., \& Rensvold, R. B. (2002). Evaluating goodness-of-fit indexes for testing measurement invariance. Structural Equation Modeling: A Multidisciplinary Journal, 9(2), 233255. doi: 10.1207/S15328007SEM0902 5

Cortina, J. M., \& Dunlap, W. P. (1997). On the logic and purpose of significance testing. Psychological Methods, 2(2), 161-172. doi: 10.1037/1082-989X.2.2.161

Cortina, J. M., \& Folger, R. G. (1998). When is it acceptable to accept a null hypothesis: no way, Jose? Organizational Research Methods, 1(3), 334-350. doi: 10.1177/109442819813004

Dick, A. S., \& Basu, K. (1994). Customer loyalty: toward an integrated conceptual framework. Journal of the Academy of Marketing Science, 22(2), 99-113. doi: 10.1177/0092070394222001

Drogendijk, R., \& Holm, U. (2012). Cultural distance or cultural positions? Analysing the effect of culture on the HQ-subsidiary relationship. International Business Review, 21(3), 383-396. doi: 10.1016/j.ibusrev.2011.05.002

Drogendijk, R., \& Slangen, A. (2006). Hofstede, Schwartz, or managerial perceptions? The effects of different cultural distance measures on establishment mode choices by multinational enterprises. International Business Review, 15(4), 361-380. doi: 10.1016/j.ibusrev.2006.05.003

Durvasula, S., Andrews, J. C., Lysonski, S., \& Netemeyer, R. G. (1993). Assessing the cross-national applicability of consumer behavior models: a model of attitude toward advertising in general. Journal of Consumer Research, 19(4), 626-636. doi: 10.1086/209327

Farber, B., \& Wycoff, J. (1991). Customer service: evolution and revolution. Sales \& Marketing Management, (May), 44-51.

Fornell, C. (1992). A national customer satisfaction barometer: the Swedish experience. Journal of Marketing, 56(1), 6-21. doi: 10.2307/1252129

Fornell, C., Johnson, M. D., Anderson, E. W., Cha, J., \& Bryant, B. E. (1996). The American customer satisfaction index: nature, purpose and findings. Journal of Marketing, 60(4), 7-18. 
Gardner, M. J., \& Altman, D. G. (1986). Confidence intervals rather than P values: estimation rather than hypothesis testing. British Medical Journal, 292(6522), 746-750. doi: 10.1136/bmj.292.6522.746

Gerpott, T., Rams, W., \& Schindler, A. (2001). Customer retention, loyalty and satisfaction in the German mobile cellular telecommunications market. Telecommunications Policy, 25(4), 249269. doi: 10.1016/S0308-5961(00)00097-5

Goldstein, H., \& Healy, M. J. R. (1995). The graphical presentation of a collection of means. Journal of the Royal Statistical Society, 158(1), 175-177. doi: 10.2307/2983411

Goodrich, K., \& Mooij, M. de (2011). New technology mirrors old habits: online buying mirrors cross-national variance of conventional buying. Journal of International Consumer Marketing, 23(3/4), 246-259. doi: 10.1080/08961530.2011.578061

Hair, J. F., Black, W. C., Babin, B. J., \& Anderson, R. E. (2009). Multivariate data analysis (7th ed.). Upper Saddle River: Prentice-Hall.

Hambleton, R. K. (1993). Translating achievement tests for use in cross-national studies. European Journal of Psychological Assessment, 9(1), 57-68.

Hofstede, G. (n.d.). Dimension data matrix. Retrieved from http://www.geerthofstede.com/media/654/6\%20dimensions\%20for\%20website\%2020101123.txt

Hofstede, G., Hofstede, G. J., \& Minkov, M. (2010). Cultures and organizations: software of the mind (3rd ed.). New York: McGraw Hill.

Hoyle, R. H. (1995). Structural equation modeling: concepts, issues, and applications. Thousand Oaks, CA: Sage Publications.

Hu, A. W., \& Hwang, I. S. (2006). Measuring the effects of consumer switching costs on switching intention in Taiwan mobile telecommunication services. The Journal of American Academy of Business, 9(1), 75-85.

Hu, L.-T., \& Bentler, P. M. (1998). Fit indices in covariance structure modeling: sensitivity to underparameterized model misspecification. Psychological Methods, 3(4), 424-453. doi: 10.1037//1082-989X.3.4.424

Hult, G. T. M., Ketchen, D. J., Jr, Griffith, D. A., Finnegan, C. A., Gonzalez-Padron, T., Harmancioglu, N., Huang, Y., Talay, M. B., \& Cavusgil, S. T. (2008). Data equivalence in cross-cultural international business research: assessment and guidelines. Journal of International Business Studies, 39(6), 1027-1044. doi: 10.1057/palgrave.jibs.8400396

Jones, M. A., Mothersbaugh, D. L., \& Beatty, S. E. (2000). Switching barriers and repurchase intentions in services. Journal of Retailing, 76(2), 259-274. doi: 10.1016/S0022$4359(00) 00024-5$

Jones, M. A., Mothersbaugh, D. L., \& Beatty, S. E. (2002). Why customers stay: measuring the underlying dimensions of services switching costs and managing their differential strategic outcomes. Journal of Business Research, 55(6), 441-450. doi: 10.1016/S0148-2963(00)00168-5

Kandogan, Y. (2012). An improvement to Kogut and Singh measure of cultural distance considering the relationship among different dimensions of culture. Research in International Business and Finance, 26(2), 196-203. doi: 10.1016/j.ribaf.2011.11.001

Kim, M. K., Park, M.-C., \& Jeong, D.-H. (2004). The effects of customer satisfaction and switching barrier on customer loyalty in Korean mobile telecommunication services. Telecom Policy, 28(2), 145-159. doi: 10.1016/j.telpol.2003.12.003 
Klemperer, P. (1987). Markets with consumer switching costs. The Quarterly Journal of Economics, 102(2), 375-394. doi: 10.2307/1885068

Klemperer, P. (1995). Competition when consumers have switching costs: an overview with applications to industrial organization, macroeconomics, and international trade. Review of Economic Studies, 62(4), 515-539. doi: 10.2307/2298075

Kline, R. B. (1998). Principles and practice of structural equation modeling. New York: Guilford Press.

Kogut, B., \& Singh, H. (1988). The effect of national culture on the choice of entry mode. Journal of International Business Studies, 19(3), 411-432. doi: 10.1057/palgrave.jibs.8490394

Lee, S. W., Kim, D. J., \& Park, M. C. (2004, January). Demand for number portability in the Korean mobile telecom market. Proceedings of the Hawaii International Conference on System Sciences, Big Island, HW, USA, 37.

Leng, C. Y., \& Botelho, D. (2010). How does national culture impact on consumers decision-making styles? A cross cultural study in Brazil, the United States and Japan. Brazilian Administration Review, 7(3), 260-275. doi: 10.1590/S1807-76922010000300004

Leo, C., Bennett, R., \& Härtel, C. (2005). Cross-cultural differences in consumer decision-making styles. Cross Cultural Management, 12(3), 32-62. doi: 10.1108/13527600510798060b

Leung, K., Bhagat, S., Buchan, R., Erez, M., \& Gibson, C. (2005). Culture and international business: recent advances and their implications for future research. Journal of International Business Studies, 36(4), 357-378. doi: 10.1057/palgrave.jibs. 8400150

Lichtenstein, D., Ridgway, N., \& Netemeyer, R. (1993). Price perceptions and consumer shopping behavior: a field study. Journal of Marketing Research, 30(2), 234-245. doi: 10.2307/3172830

Lim, H., Widdows, R., \& Park, J. (2006). M-loyalty: winning strategies for mobile carriers. Journal of Consumer Marketing, 23(4), 208-218. doi: 10.1108/07363760610674338

Loehlin, J. C. (1992). Latent variable models: an introduction to factor, path, and structural analysis. Hillsdale, NJ: Lawrence Erlbaum.

Magnusson, P., Wilson, T., Zdravkovic, S., Zhou, J., \& Westjohn, S. (2008). Breaking through the cultural clutter: a comparative assessment of multiple cultural and institutional frameworks. International Marketing Review, 25(2), 183-201. doi: 10.1108/02651330810866272

Manrai, L., \& Manrai, A. (2011). Cross-cultural and cross-national consumer research in the global economy of the twenty-first century. Journal of International Consumer Marketing, 23(3/4), 167-180. doi: 10.1080/08961530.2011.578056

Matos, C. A., Fernandes, D. H., von der, Leis, R. P., \& Trez, G. (2011). A cross-cultural investigation of customer reactions to service failure and recovery. Journal of International Consumer Marketing, 23(3/4), 211-228. doi: 10.1080/08961530.2011.578058

Mullen, M. R. (1995). Diagnosing measurement equivalence in cross-national research. Journal of International Business Studies, 26(3), 573-596. doi: 10.1057/palgrave.jibs.8490187

Ng, S. I., Lee, J. A., \& Soutar, G. N. (2007). Tourists' intention to visit a country: the impact of cultural distance. Tourism Management, 28(6), 1497-1506. doi: 10.1016/j.tourman.2006.11.005

Oliver, R. L. (1996). Satisfaction: a behavioral perspective on the consumer. New York: McGrawHill. 
Patterson, P. G., \& Smith, T. (2003). A cross-cultural study of switching barriers and propensity to stay with service providers. Journal of Retailing, 79(2), 107-120. doi: 10.1016/S00224359(03)00009-5

Peters, T. (1988). Thriving on chaos. New York: Alfred A. Knopf.

Porter, M. (1998). Competitive strategy: techniques for analyzing industries and competitors. New York: The Free Press.

Seo, D., Ranganathan, C., \& Babad, Y. (2008). Two-level model of customer retention in the US mobile telecommunications service market. Telecommunications Policy, 32(3/4), 182-196. doi: 10.1016/j.telpol.2007.09.004

Shin, D. H. (2006). A study of mobile number portability effects in the United States. Telematics and Informatics, 24(1), 1-14. doi: 10.1016/j.tele.2005.11.002

Shin, D. H., \& Kim, W. Y. (2008). Forecasting customer switching intention in mobile service: An exploratory study of predictive factors in mobile number portability. Technological Forecasting \& Social Change, 75(6), 854-874. doi: 10.1016/j.techfore.2007.05.001

Sin, L. Y. M., Cheung, G. W. H., \& Lee, R. (1999). Methodology in cross-cultural consumer research: a review and critical assessment. Journal of International Consumer Marketing, 11(4), 75-96. doi: 10.1300/J046v11n04_05

Steenkamp, J. E. M., \& Baumgartner, H. (1998). Assessing measurement invariance in cross-national consumer research. Journal of Consumer Research, 25(1), 78-107. doi: 10.1086/209528

Turel, O., \& Serenko, A. (2006). Satisfaction with mobile services in Canada: an empirical investigation. Telecommunications Policy, 30(5/6), 314-331. doi: 10.1016/j.telpol.2005.10.003

Tyron, W. W. (2001). Evaluating statistical difference, equivalence, and indeterminacy using inferential confidence intervals: an integrated alternative method of conducting null hypothesis statistical tests. Psychological Methods, 6(4), 371-386. doi: 10.1037//1082-989X.6.4.371

Weiss, A. M., \& Anderson, E. (1992). Converting from independent to employee salesforces: the role of perceived switching costs. Journal of Marketing Research, 29(1), 101-115.

Yoo, B., Donthu, N., \& Lenartowicz, T. (2011). Measuring Hofstede's five dimensions of cultural values at the individual level: development and validation of CVSCALE. Journal of International Consumer Marketing, 23(3/4), 193-210. doi: 10.1080/08961530.2011.578059 


\section{APPENDIX}

\section{Measurement Scales}

\section{Service Performance}

I think that my current carrier provides satisfying services.

My connections are always clear. (*)

I think that services I get from my current carrier when I call them by telephone are valuable.

I think that services I get from my current carrier when I call them personally are valuable. $\left(^{*}\right)$

My bill is always correct and easy to check. (*)

I am satisfied with information I get from my carrier.

\section{Service Value}

I think the price for the mobile service is reasonable.

I think the price for my mobile service is adequate to my needs.

The price for my mobile service is the best in the market.

I think the monthly charge for my mobile use is reasonable. (*)

\section{Customer Satisfaction}

I am satisfied with my current carrier.

I feel I was right when I chose my current carrier.

I would recommend my current carrier to a friend.

In general, I speak well about my current carrier.

I would like to keep the relationship with my current carrier.

\section{Switching Costs}

It takes a lot of time to get information about other carriers.

It would take a lot of time to change carriers.

I am not sure what the level of service would be if I switched to a new carrier. $(*)$

It would take a lot of effort to change carriers.

\section{Contractual Lock-in}

I feel locked in to this carrier.

I will not change carriers because I would pay a fine for breaching contractual agreements.

There are procedural hassles to switch service. $(*)$

\section{Switching Barriers}

It would be difficult for me to use other carriers. $\left(^{*}\right)$

In general it would be a hassle changing carriers.

It would be complicated for me to change carriers.

\section{Switching Intention}

I intend to switch carriers.

I shall need services of another carrier.

I would not continue to have service from my current carrier.

Note. $(*)$ indicates items dropped from the final models. 